\title{
Implementing Automated Power Outlet Distribution Control System using Electronic Wastes
}

\author{
Dr. Akinola. S. Olayinka ${ }^{1}$, Dr. Wilson Nwankwo ${ }^{2}$, Tosin. C. Olayinka ${ }^{3}$, M.O. Osiele ${ }^{4}$ \\ Department of Physics, Edo University Iyamho, Edo State, Nigeria ${ }^{1}$ \\ Associate Professor, Department of Computer Science, Wellspring University, Benin City, Nigeria $^{2}$ \\ Department of Computer Science, Samuel Adegboyega University, Ogwa Edo State Nigeria ${ }^{3}$ \\ Department of Physics, Delta State University, Abraka, Delta State, Nigeria ${ }^{4}$
}

\begin{abstract}
Electronic dumping is a global challenge and fortunately majority of these wastes could be recycled can provide an economically viable and healthy environment as well as offer new insights on how potential sources of environmental hazards could be transformed into useful products. In this paper, we present data used during the creation of an automated power outlet system from electronic wastes. Automated power control and distribution systems are important in reducing the cost of energy utilization in homes, offices, and in industrial environment. Usually, as energy utilization increases, the costs increases. The need to prioritize and conserve scarce energy becomes imminent especially in low income earning environments. Often times, the cost of acquisition of such devices may be high. This paper reflects on how components extracted from electronic wastes could be harnessed to produce computercontrolled power outlet system.
\end{abstract}

Keywords: Automated Power Distribution Control, Microcontroller, Electronic wastes, Environment, Power management

\section{INTRODUCTION}

Electronic waste also called E-waste is often used in different ways. In simple terms, it is a generalized name for electrical and electronic products approaching the end or at the end of its useful life [1-3].

E-waste has also been defined to imply all electric and electronic devices or components that have lost their primordial values especially to their original owners [4]. Lundgren [5] refers to e-waste as discarded electrical and electronic equipment and components.

According to Puckett et al[6] E-waste includes a growing range of electronic devices such as refrigerators, air conditioners, cell phones, consumer electronics, computers, etc. that have been discarded by their users. Technopedia[7] describes electronic waste as "the disposal of broken and/or obsolete electronic components and materials". Electronic waste may be valuable and recyclable, for example, RAM chips, circuit boards, etc. [8]. The actual composition of electronic wastes is diverse and differs across products. These wastes have been found to contain a thousand different substances often classified into hazardous and non-hazardous groups. Commonly recognized ewaste components are plastic casings, ferrous and non-ferrous metals, activated glass, printed circuit boards (PCB), concrete, wood, batteries, cathode-ray tubes, lead capacitors, etc. A larger chunk of these wastes are shipped to lessdeveloped and developing countries [9] where such contributes to increasing environmental pollution and hazards owing to challenges poor waste disposal systems.

Due to the advancement in technology and increased manufacturing of electronic devices in developed countries, the trend in the generation of e-wastes has become a global concern. In the last few years, there has been various international calls for action in respect of the need to develop strategic interventions for dealing with the challenge posed by e-waste. These calls include but not limited to: The Libreville Declaration on Health and Environment in Africa which was the first Inter-Ministerial Conference held in 2008 to consolidate on the commitments and declarations that bear on health and environmental health and safety [10]; the Busan Pledge for Action on Children's Environmental Health[11-12] which emanated from the third World Health Organization(WHO) conference on Children's health and the Environment held in Busan, Korea in June 2009 , and additions made to the Global Plan of Action of the Strategic Approach to Integrated Chemical Management(SAICM)[13] issued at the International Conference on Chemical Management(ICCM3) in Nairobi Kenya in September 2012. 
Though, there are a number of national and international initiatives and programmes that are geared towards addressing the e-waste management as it affects environmental pollution, Health, and Safety, the major bottlenecks to the success of the myriad programmes has been the implementation process. As stated earlier, e-waste may contain valuable as well as recyclable material. Accordingly, this paper on production of automated power outlet distribution system explores the re-use option as a way of reducing the volume of electronic wastes dumping.

Potential energy savings and reduced running costs can be achieved through automation [14-16]. As desirable as automated control systems are, there is often the attendant cost of procurement and deployment especially in developing countries. Alternative solutions to costly sophisticated systems is likely to attract more attention especially where there exist relatively good sources of production materials. The data presented in this article is a description of materials for the production of majority of which are synthesized from electronic computer dumps. Emphasis is on the production of cheap and cost-effective automated power outlet control and distribution system through the use of computer hardware dumps as basic materials in addition to fewer refined and cheap discrete components. Component by component specifications are represented by way of diagrams in the form of figures, tables, etc. as well as description of system design tools and program model. Access to Electronic dumps; careful extraction of useful components such as motherboards, ROM, RAM, Metal Casing, Extracted component functionality testing, Acquisition of Micro-controller (where necessary), Assembly of components, High level programming and automated microprogramming are summarily discussed. Table 1 shows the basic statistics of the components used.

Table 1: Component Specification

\begin{tabular}{|l|l|l|}
\hline S/N & Description & Source \\
\hline 1 & $\begin{array}{l}\text { PC with 512MB RAM, 50GB Hard running } \\
\text { Windows 2000 or XP }\end{array}$ & Discarded PC Dumps \\
\hline 2 & USB-to-Serial cable & Discarded PC Dumps \\
\hline 3 & 12V Step down transformer & Purchase \\
\hline 4 & Diode Bridge rectifier & Purchase \\
\hline 5 & 16x2 LCD & Purchase \\
\hline 6 & $\begin{array}{l}\text { Microcontroller with Solid state isolation( } \\
\text { Intel 8051/8052) }\end{array}$ & Discarded PC Dumps \\
\hline 7 & $\begin{array}{l}\text { Capacitor filter } \\
\text { DC step-down } \\
\text { regulatorIC7805) }\end{array}$ & Discarded PC Dumps \\
\hline 8 & RS232 Voltage converter & Purchase \\
\hline 9 & Motherboard(circuit board) & Purchase \\
\hline 10 & Soldering iron and Lead & Discarded PC Dumps \\
\hline 11 & & Purchase \\
\hline
\end{tabular}

Figure 1 is a block diagram that reflects the assemblage of the various components of the system.

\section{PROBLEM IDENTIFICATION}

Electronic dumping poses serious global environmental challenge especially in the Eastern, Central, and Sub-Saharan Africa where much dumping of second-hand electronic goods from Europe and the Americas is predominant. Electronic waste disposal is a difficult venture hence recycling is a welcome development as it is a way of generating

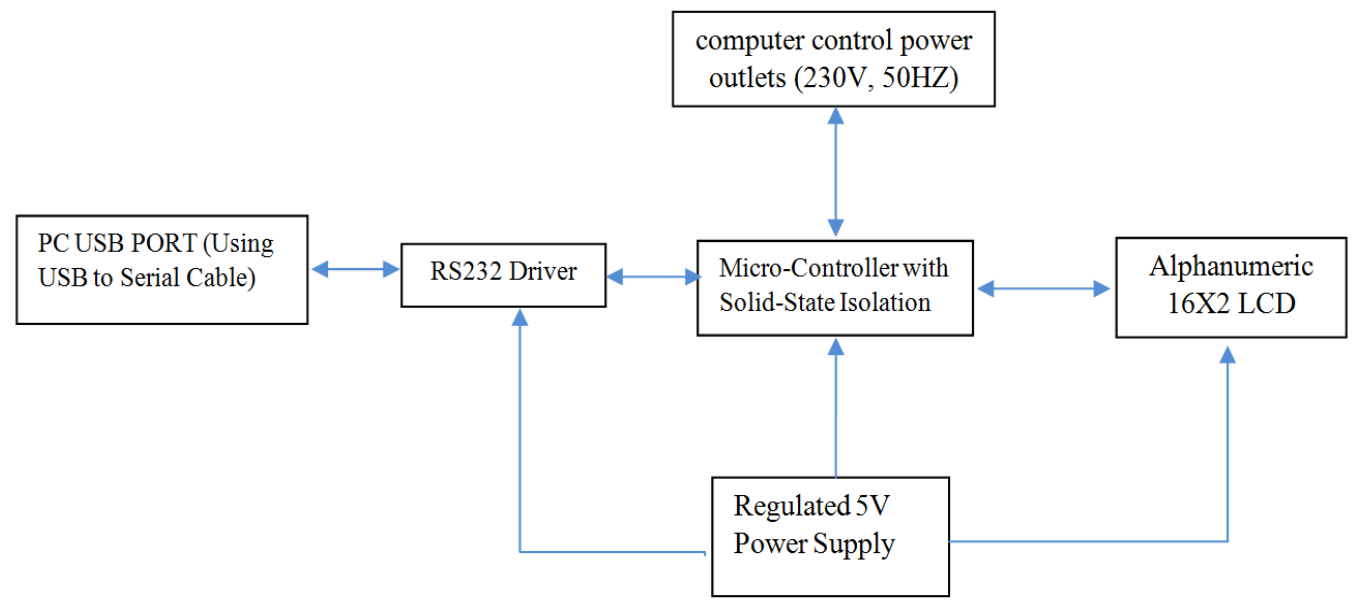

Figure 1: Block Diagram for Automated Power Distribution Outlet System 
economically viable products, reducing environmental pollution thereby boosting healthy environment as well as offer new insights on how potential sources of environmental hazards could be transformed into useful products. New automated power control systems for home and office uses may not be cost-effective especially to low income earners; exploring other options may lead to the development of cheaper and effective solutions. Extraction, fabrication, assembly, integration and deployment of a cost-effective power utilization solution can ignite new line of small to medium scale production industries thereby creating jobs and improving gross domestic product of the country in question.

Homes, offices, and industries can conserve energy and reduce energy costs by deploying such automated power outlet distribution system like the one described in this article

\section{EXPERIMENTAL DESIGN, MATERIALS AND METHODS}

Materials: The materials used are: PC, USB-serial cable, Step-down transformer, Diode bridge rectifier, capacitors, Microcontroller, Microsoft Visual studio IDE, 16x2 LCD, transistors, DC Step-down converter.

Material selection/ acquisition: The materials are classified into two namely: hardware and software. Some hardware components are sourced from electronic dumps which attracts little or no costs. However, other components as shown in Table 1 above are purchased. The components sourced from dumps are carefully extracted and tested to ensure workability. The design of the system is divided into three sections:
a. Power supply circuitry
b. Microcontroller and LCD integration
c. High-level programming of Application frontend

Power Circuitry: Every electrical or electronic device in use or intended for use require a power supply. The AC supply in use at this geographical area is $220 \mathrm{~V} 60 \mathrm{~Hz}$, but this power cannot be used directly on electronic devices. In other words, the AC power has to be converted to the required form usually a DC and in this case $5 \mathrm{~V}$ DC which is what the Microcontroller in this design requires. Power electronic converters are of various types e.g. step-down converter, step-up converter, voltage stabilizer, AC to DC converter, DC to DC converter, DC to AC converter, etc. but we used a $12 \mathrm{~V}$ step-down converter to convert the $220 \mathrm{~V}$ AC mains supply to $12 \mathrm{~V}$ AC.

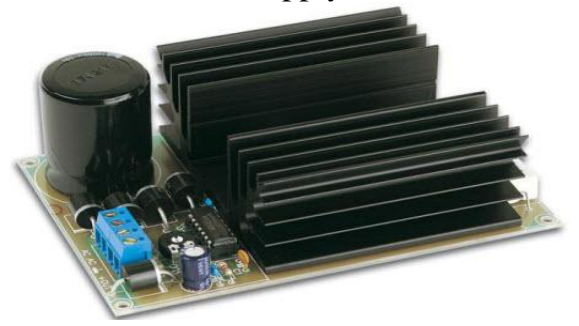

Figure 2: Step-down converter

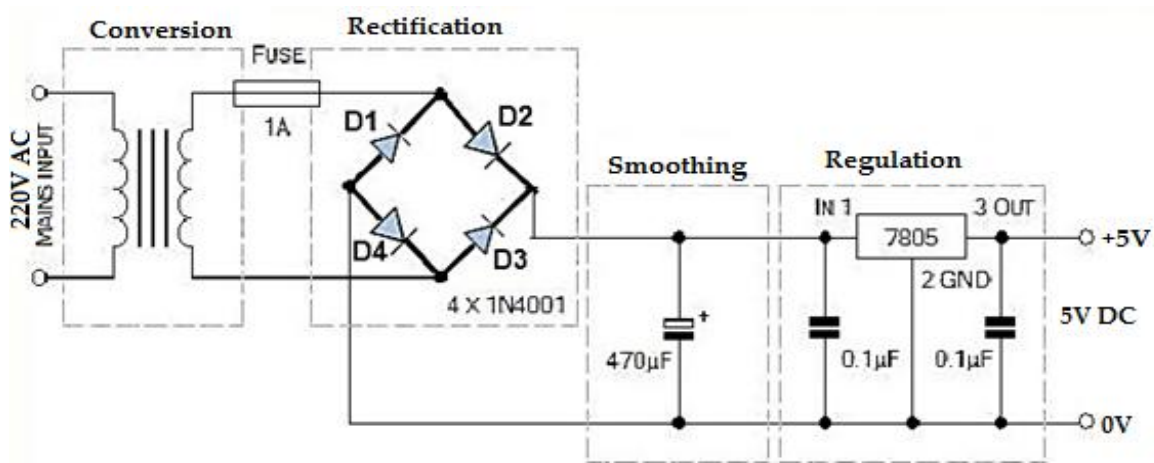

Figure 3: Conversion, Rectification, Smoothing, and Regulation of $220 \mathrm{~V}$ AC to $5 \mathrm{~V}$ DC for Use by the Microcontroller

Figure 2 shows a 12V step-down converter circuit component. The $12 \mathrm{~V}$ AC output of stepdown transformer is still not in a useful form and have to be converted into an equivalent DC form. This is achieved through rectification, smoothing, and regulation. That is the $12 \mathrm{~V}$ AC from the step-down transformer(converter) is sent through a bridge rectifier, smoothened through the use of capacitor filters as the DC obtained during rectification is not pure DC but pulses. Smoothing filters the pulsating DC into a pure DC. The smoothened voltage is subsequently regulated using the 5V DC regulator. Figure 3 shows a schematic for the rectification, smoothing, and regulation process. 
Vol. 7, Issue 9, September 2018

Microcontroller and LCD integration: This phase involved the connection of the relevant Microcontroller connectors to the LCD, regulated voltage $(5 \mathrm{~V})$ and the input power from the power distribution outlets(sockets). Four sockets were used in this experiment. Connection is achieved through soldering the connectors with the Soldering iron and lead metal. Figure 4 shows the HD44780U 16x2 LCD module. The LCD module is to provide display for user interaction with the Microcontroller via the High level program that runs on the PC. The LCD is a $16 x 2$ display allowing the display of sixteen characters (16 columns) in any of the two rows(lines).

Table II presents the specifications of the Intel 8052 8-bit Microcontroller.

Table II: Intel 8052 8-Bit Microcontroller Specifications

\begin{tabular}{|l|l|}
\hline Clocks per instruction cycle (fewer is better) & 12 \\
\hline Timers & 3 \\
\hline Watchdog Timer & No \\
\hline UARTs/serial ports & 1 \\
\hline Internal DATA RAM bytes & 256 \\
\hline Internal XDATA RAM bytes & 0 \\
\hline Maximum program size without external logic & $64 \mathrm{~K}$ \\
\hline Wait-state support & No \\
\hline DMA channels & 0 \\
\hline Maximum PIO port pins & 32 \\
\hline Debug without emulator & No \\
\hline Number of interrupts & Fixed \\
\hline
\end{tabular}

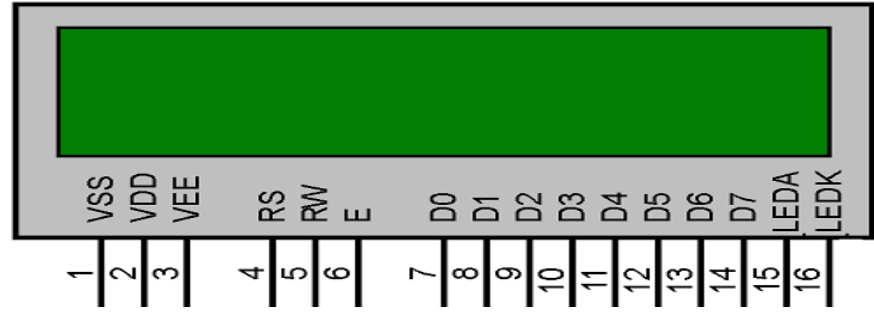

Figure 4: HD44780U Dot Matrix Liquid Crystal Display (LCD) Controller/Driver [Source: Hitachi]

Table III shows the pinout descriptions of the HD44780U dot-matrix LCD module.

Table III: Pinout Description Of The Hd44780u Dot-Matrix Liquid Crystal Display Module

\begin{tabular}{|c|c|c|c|c|c|}
\hline S/No & Pin & Label & Status & Function & Pin Connection \\
\hline 1 & Pin 1 & Ground & Source & Ground pin of LCD & $\begin{array}{l}\text { Connected to the ground of MCU/ } \\
\text { Power source }\end{array}$ \\
\hline 2 & Pin 2 & $\mathrm{VCC}$ & Source & $\begin{array}{l}\text { Supply voltage pin of } \\
\text { LCD }\end{array}$ & $\begin{array}{l}\text { Connected to supply pin of Power } \\
\text { source }\end{array}$ \\
\hline 3 & Pin 3 & V0/VEE & Control & $\begin{array}{l}\text { Used to adjust the } \\
\text { contrast of the LCD. }\end{array}$ & $\begin{array}{l}\text { Connected to a variable POT that } \\
\text { can source } 0-5 \mathrm{~V}\end{array}$ \\
\hline 4 & Pin 4 & Register Select & Control & $\begin{array}{l}\text { Toggles between } \\
\text { Command/Data Register }\end{array}$ & $\begin{array}{l}\text { Connected to a MCU pin and is } \\
\text { either } 0 \text { or } 1 \text {. } \\
0=>\text { Command Mode } \\
1=>\text { Data Mode }\end{array}$ \\
\hline 5 & Pin 5 & Read/Write & Control & $\begin{array}{l}\text { Toggles the LCD } \\
\text { between } \\
\text { Operation }\end{array}$ & $\begin{array}{l}\text { Connected to a MCU pin and is } \\
\text { either } 0 \text { or } 1 . \\
0=>\text { Write Operation } \\
1=>\text { Read Operation }\end{array}$ \\
\hline 6 & Pin 6 & Enable & Control & $\begin{array}{l}\text { To be held high to } \\
\text { perform } \text { Read/Write } \\
\text { Operation }\end{array}$ & $\begin{array}{l}\text { Connected to MCU and always held } \\
\text { high. }\end{array}$ \\
\hline 7 & $\begin{array}{l}\text { Pin } 7- \\
14\end{array}$ & Data Bits (0-7) & $\begin{array}{l}\text { Data / } \\
\text { Command }\end{array}$ & $\begin{array}{l}\text { Send Command or data to } \\
\text { the LCD. }\end{array}$ & $\begin{array}{l}\text { In } 4 \text {-Wire Mode } \\
\text { The } 4 \text { pins }(0-3) \text { are connected to } \\
\text { MCU but in } 8 \text {-Wire Mode, the } 8 \\
\text { pins }(0-7) \text { are connected to the MCU }\end{array}$ \\
\hline
\end{tabular}


Vol. 7, Issue 9, September 2018

\begin{tabular}{|l|l|l|l|l|l|}
\hline 8 & Pin 15 & LED Positive & LED & $\begin{array}{l}\text { For normal LED-like } \\
\text { operation to illuminate } \\
\text { the LCD }\end{array}$ & Connected to +5V \\
\hline 9 & Pin 16 & LED Negative & LED & $\begin{array}{l}\text { Normal } \\
\text { operation to illuminate } \\
\text { the LCD connected with } \\
\text { GND. }\end{array}$ & Connected to ground \\
\hline
\end{tabular}

Microcontroller Programming: Assembly language was used to program the micro-controller. Assembly language provide mnemonics that reflect the machine code instructions. The steps taken to write the Assembly language instructions are outlined as follows:

1. The MIDE editor was used to write the instructions which were saved in an ASCII source file. The "asm" source file above is fed to an 8052 assembler (MIDE) which converts the instructions into machine code. Prior to the machine code conversion, note that the assembler produced two files in the process: an object file and a list file with extensions ".obj" and ".lst" respectively. These files must be linked using a linker.

2. The linker program takes one or more object code files and produce an absolute object file with the extension "abs"

3. The ".abs" file is then fed into the object to hex converter $(\mathrm{OH})$ which creates a file with extension "hex". The '.hex' file is then downloaded or burnt into the ROM.

Frontend/User Interface Programming: The User interface programming is done using Microsoft Visual Basic. The frontend has three components:

a. Splash Screen - which displays welcome messages to the users.

b. Power Outlet distribution Interface - This enables the user switch ON or OFF any of the power outlet.

c. Timer - This enables user set time to turn any socket ON or OFF.

\section{RESULTS}

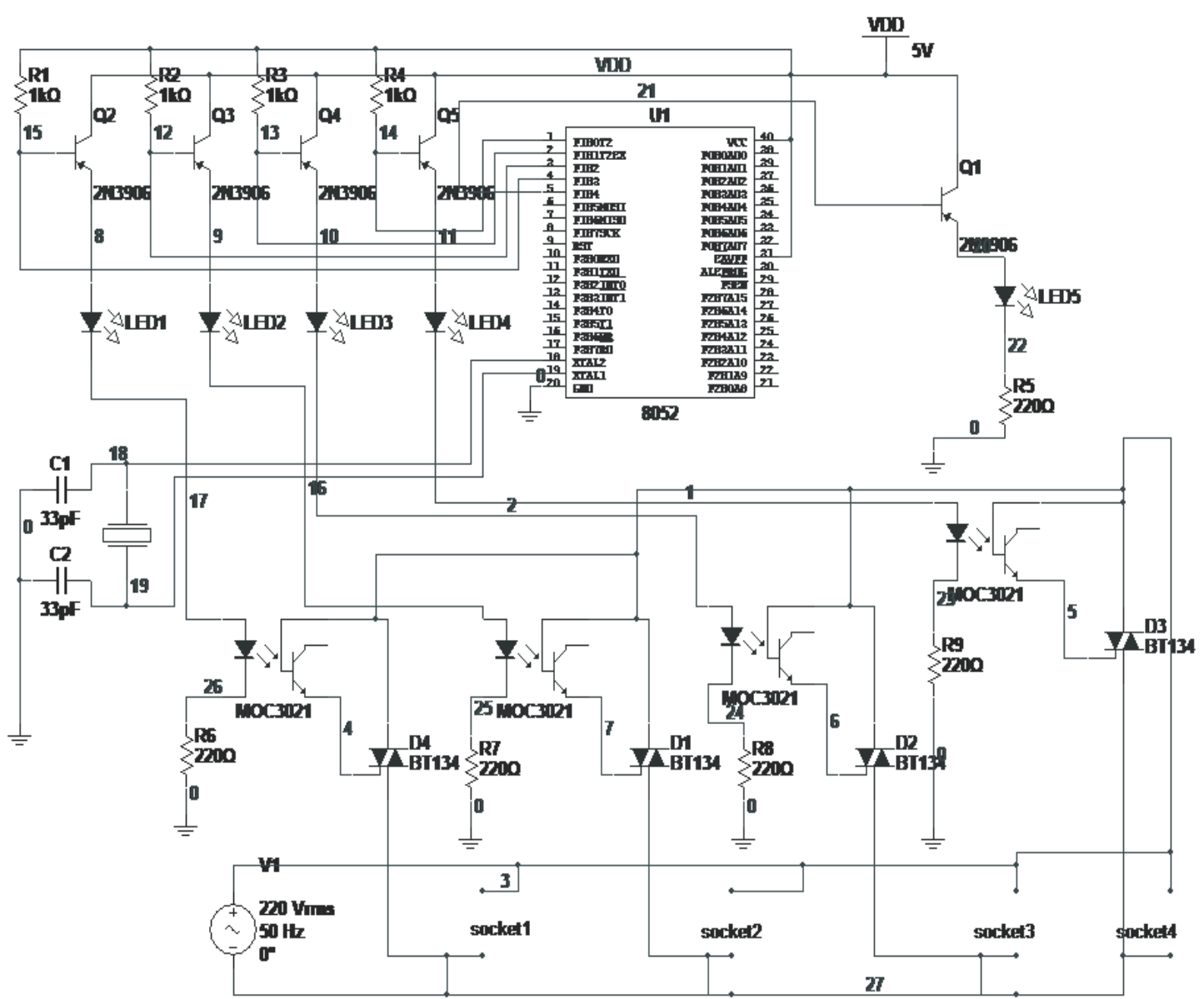

Figure 5: Schematic showing Integration of Microcontroller and LCD 


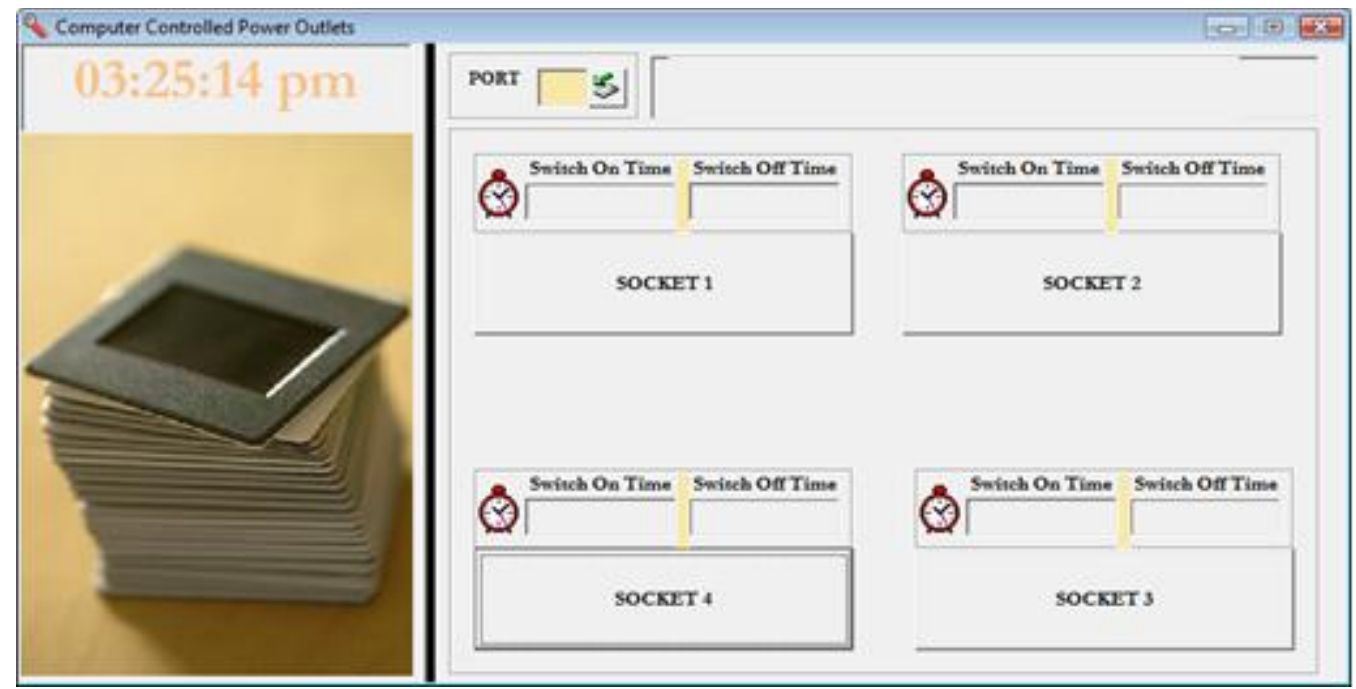

Figure 6: User interface for controlling the power distribution outlets

\section{CONCLUSION}

This paper discussed the creation of an automated power outlet distribution system using materials derived from electronic wastes. The prototype includes an interactive graphics user interface through which a user will be able to control the four power outlets attached to the PC via USB interface. With this solution, power distribution in homes or office for automation could be appropriately shared and controlled from a low-end computer system. The methods employed here could also be adapted or extended to produce sophisticated but easy to use apparatus for controlling distribution by way of a local or remote electronic device not necessarily a PC in a Production Line, Factory line automation and control, Security Systems, to mention a few.

\section{REFERENCES}

[1]. Santhanam Needhidasan, Melvin Samuel and Ramalingam Chidambaram (2014). Electronic waste - an emerging threat to the environment of urban India, Journal of Environmental Health Science \& Engineering, 12(36)

[2]. United Nations Environment Programme (UNEP). E-waste volume I: inventory assessment manual. United Nations Environmental Programme, Division of Technology, Industry and Economics, International Environmental Technology Centre, Osaka, Japan; 2007

[3]. Council of the European Parliament. Directive 2002/96/EC of the European Parliament and of the Council of 27 January 2003 on waste electrical and electronic equipment (WEEE). March 13, 2003. OJEU. 2003; 37: 24-38

[4]. Sthiannopkao S, Wong MH. (2012) Handling e-waste in developed and developing countries: Initiatives, practices, and consequences. Sci Total Environ.

[5]. Lundgren, K(2012) The global impact of e-waste: addressing the challenge. International Labour Office, Geneva.

[6]. Puckett J, Byster L, Westervelt S(2002). Exporting Harm: The high-tech trashing of asia, the basel action network (BAN) and Silicon Valley Toxics Coalition (SVTC), 2002. Available at http://www.ban.org/E-waste/technotrashfinalcomp.pdf.

[7]. Technopeda. https://www.techopedia.com/definition/2108/electronic-waste-e-waste

[8]. Osibanjo, O. \& Nnorom, I.C. (2007). The challenge of electronic waste (e-waste) management in developing countries, Journal of Waste Management Research, 26(6).

[9]. UN Environment Programme. E-waste, volume 1: inventory assessment manual. UN Environment Programme, Nairobi; 2007

[10]. WHO (2008 August) Libreville Declaration on Health and Environment in Africa, Libreville. https://www.ehrn.co.za/download/libreville_decla ration.pdf

[11]. WHO(n.d.). Children's environmental health: E-waste. Available at http://www.who.int/ceh/risks/ewaste/en/

[12]. WHO (2009 June). 3rd International Conference on Children's Health and the Environment

[13]. Strategic Approach to International Chemicals Management (2012 July). Proposed additions to the Global Plan of Action, International Conference on Chemicals Management, Nairobi, Kenya

[14]. Becker, M. \& Knoll,P.(2014) Energy Savings and Energy Efficiency through Building Automation and Control, The REHVA European HVAC Journal, Vol.5.

[15]. Grigoryeva, S., Baklanov, A., Titov, D., Sayun, V. \& Grigoryev, E.(2017). Analysis energy efficiency of automated control system of LED lighting, Proceedings of the International Siberian Conference on Control and Communications (SIBCON), IEEE

[16]. Duszynski, M.M (2016). Saving Energy and Reducing Costs Through Better Use of Building Automation Systems, Energy Exchange: Federal Sustainability for the Next Decade, US Department of Energy. 